\title{
The power to respond
}

\author{
The humanitarian aid sector is transforming the ways it uses and deploys energy as crises become more complex \\ and the effects of climate change are increasingly felt.
}

$\mathrm{t}$ won't have escaped the attention of anyone following global events that refugee crises are becoming increasingly intense and protracted. Supporting growing refugee communities is also becoming more challenging, particularly against a backdrop of increasingly constrained funding and rising need. How humanitarian agencies provide assistance is changing in response to these factors and in line with agreements on minimum standards: there is increasing engagement with refugee communities to better understand their needs and empower them to help deliver solutions, as well as growing interaction with the private sector.

Attitudes are also changing around how energy is considered within the delivery of humanitarian aid. Energy is a critical component underlying many functions of humanitarian assistance and of supporting people's lives. It is used in the delivery of clean water, sanitation, medical assistance, shelter, transport and lighting. More than that, it provides security and safety in ways that many of us take for granted. In protracted crises, it is essential to support the delivery of education and ongoing healthcare, and to create opportunities for livelihoods and businesses.

At the same time, humanitarian responders often work in contexts where the environmental impacts of climate change and unsustainable fuel use are clear and constant threats. In these situations, communities and the humanitarian responders who work with them have to balance necessary life-saving practices with long-term consequences, considering not only environmental and economic sustainability but also wider implications for the security and safety of affected populations. An oft-cited example is the need for biomass for cooking or heating. In the absence of other solutions, foraging for firewood becomes the obvious option. This has negative environmental impacts through deforestation and has implications for health and air quality; but it also creates tension with local communities and raises safety concerns for those doing the foraging, who are often women and young girls.

The environmental impact of energy in refugee settings is increasingly being addressed through a more holistic approach to energy in humanitarian aid strategies and interventions that puts more attention on sustainable energy solutions. This Focus issue explores the different ways that this changing attitude is affecting energy solutions for refugees. Four key dimensions are of particular interest here: the use of inclusive design approaches to improve energy access; the role data play in developing better interventions and operations; the opportunity that marketbased solutions present; and the importance of policy frameworks to support sustainable practices and programmes.

As Sarah Rosenberg-Jansen at the University of Oxford and Tracy Tunge and Timothy Kayumba at Practical Action outline in their Comment, inclusive design approaches bring together humanitarian and development agencies, the private sector, refugees and their host communities to co-develop energy services that better meet refugees' needs. These approaches put refugees and host communities at the heart of projects, enabling them to be more than just beneficiaries of aid.

The success of inclusive approaches will be determined to some extent by sound assessments. Data play a pivotal role there, as well as in assessing delivery of energy across the spectrum of goods and services required to support refugees. However, as Owen Grafham at Chatham House and Phil Sandwell at Imperial College London discuss in their Comment, there is currently a lack of data on humanitarian energy interventions, as well as a lack of coordination on its collection, use and sharing. Overcoming these obstacles could dramatically improve energy outcomes and aid delivery. There is an opportunity here for the wider research community to offer its experience and insights towards this challenge.

These two factors are important in the delivery of energy goods and services, but they are also dependent on the existence of markets and market systems to support them. Crucially, as outlined in a Comment by Anoushka Boodhna, Corrie Sissons and Jessica Fullwood-Thomas at Oxfam, if market-based approaches and market systems are developed well, they can both foster more effective access to energy and provide a long-term selfsustaining environment that persists after aid is removed. They can also work to counterbalance prevailing power dynamics towards more equitable ends.

Policy and governance are also central to the long-term success and sustainability of these new approaches to energy delivery. However, there can often be conflict between policy at different scales: local, national or international; short term or long term. In their Comment, Suzanna Huber at the United Nations Institute for Training and Research and Eva Mach at the International Organization for Migration discuss the complex dynamics arising from these diverse priorities and from the myriad of different displacement contexts, which hamper progress towards an overarching framework. Recent examples from the field illustrate that there can be no one size fits all policy approach but do point to useful principles that can be adopted towards more sustainable energy access.

Climate change also plays an increasingly pivotal role in how humanitarian organizations think about energy. As Andrew Harper, Director of Programmes at the United Nations High Commissioner for Refugees, describes in his Q\&A, climate change isn't just affecting how organizations think about their own energy use: it has become a 'threat multiplier'. Areas that host refugees are typically already vulnerable to the worst impacts of climate change, which leads to issues around resources or governance. At the same time, climate change is beginning to affect displacement in ways that require further attention and understanding.

The humanitarian sector is undergoing an energy transition, whose challenges echo many of the challenges facing the energy transition in stable contexts. Across the dimensions highlighted in this Focus, it's clear that there are many opportunities for the research community to engage, both to offer support but also to learn from the humanitarian sector's experiences. We hope that the attention drawn here to these issues helps engender further discussions across the academic, humanitarian and development spheres, for the betterment of all.

Published online: 12 December 2019 https://doi.org/10.1038/s41560-019-0528-6 